Journal of Qualitative Criminal Justice \& Criminology

\title{
Book Review | Lifers: \\ Seeking Redemption in Prison
}

Brian P. Schaefer ${ }^{1}$

${ }^{1}$ University of Louisville

Published on: Oct 01, 2013

Updated on: Aug 17, 2020

DOI: $10.21428 / 88 d e 04 a 1.51 d d a 7 f 4$

License: Creative Commons Attribution 4.0 International License (CC-BY 4.0). 
John Irwin. Lifers: Seeking Redemption in Prison. Routledge, 2009; 140 pp.; ISBN: 9780415801980.

The late John Irwin had a distinguished career researching the realities of American prisons and the associated cultures and norms that develop within these institutions. His legacy of research challenged widely held beliefs about the nature of imprisonment and reentry and introduced us to new frameworks to understand the prison industry. Along with famous works such as The Felon (1970), The Jail (1985), and The Warehouse Prison (2004), Irwin was instrumental in introducing Convict Criminology to academe, giving a voice to those who experienced the pains of imprisonment. In his final book, Lifers: Seeking Redemption Prison (2009), Irwin once again explores the challenges of prison, examining the complexities of individuals sentenced to life in prison. Irwin attempts to challenge the myths associated with these individuals and to humanize the criminal other. He uses in-depth interviews to take the reader through the lives of 17 individuals who are serving a life sentence for homicide or second-degree homicide in San Quentin Prison in California.

The depth of Irwin's argument is found in chapters 2 through 5. In chapters 2 and 3, Irwin discusses the backgrounds of each offender, noting that many of the crimes were a result of immature decisions, emotions, or poor life circumstances that culminated in an act of homicide or second degree homicide and, in a few stances, likely wrongful convictions. In each instance, the lifers were sentenced to life in prison and faced decades in prison, but with the possibility of being released on parole. In Chapter 4, Irwin discusses how the lifers awaken and recognize that what they did was wrong and come to the realization that they need to improve their lives. It is at this point that the lifers begin to take advantage of rehabilitation programs such as educational and vocational training. Following the awakening, the lifers seek atonement (Chapter 5). The lifers pass through multiple stages of atonement working through their shortcomings and then attempt to acquire a pro-social orientation. The final stage of atonement involves making preparation to carry out this orientation to earn parole and be released from prison. These four chapters instill the thought processes and emotions that the lifers have experienced and their desire to change their lives; there is an emphasis on the fact that even so-called "evil" people can turn their lives around and, in doing so, challenge the dominant discourses of the American criminal justice system.

The humanization of lifers is an important contribution, but the most important component of Irwin's argument is shown by taking this analysis and placing it in the wider context of social conflicts, including the politics of prison reform and the difficulties of reentry. Irwin notes that states are facing increased budgetary constraints due to the high number of prisoners, long sentence lengths, and the high medical costs of elder prisoners. As prisoners are released, additional complication arise, because many of these individuals are not provided with any assistance in obtaining basic necessities such as 
housing, work, or transportation. For lifers, this is particularly troubling, for they have spent decades in prison and have watched society pass them by. Without support, it makes it difficult for lifers or any of the thousands of prisoners returning to society each year to turn their lives around. It is through raising the issue of reentry that Irwin makes one of his most important points: that prisoners and exprisoners should have a voice in in the reentry discussion. Irwin recognizes that prisoners and exprisoners, having experienced the difficulties of reentry, have a unique set of insights and knowledge that can assist in developing better policy.

Additional research should continue Irwin's work by examining the challenges prisoners face when returning to society, as well as how prisoners change their lives around while inside the prison walls. Irwin's study is a good start to this project, but the small samples size and the narrow population-lifers convicted of murder and residing in one prison-is not representative of prisoners in the United States. Additional research is needed that asks prisoners who a wide-range of sentences and convictions to explain the challenges of prison and reentry. While this research is being conducted, researchers should remain reflexive in the challenges they face when researching prison populations to inform the discipline of techniques needed to overcome barriers often associated with prison research (Jewkes, 2012).

Notwithstanding the limitations and the need for future research, Irwin eloquently captures the complexities of prisoners sentenced to life. These 17 individuals shared common upbringings that often consisted of difficult life circumstances or bad choices driven by heightened emotions. Despite the seriousness of the crimes committed by these individuals, Irwin shows how even violent offenders can be transformed through their years spent in prison and develop the desire to improve their lives. Irwin confronts the myth that murderers are evil people who need to be locked up forever and, instead, shows that these long-prison sentences are inhumane; the lack of reentry programs are harming society. In his final book, Irwin successfully contests notions about prisons and challenges the reader to think differently about prisoners, therefore his book would be a valuable source for undergraduate courses or a supplement to graduate seminars on prison. In true Convict Criminological fashion, Irwin is able to teach the reader about prison using the perspectives and insights of prisoners to expose the contradictions in the American prison system.

\section{References}

Irwin, J. (1970). The felon. Los Angeles, CA: University of California Press.

Irwin, J. (1985). The jail: Managing the underclass in American society. Los Angeles, CA: University of California Press.

Irwin, J., \& Owen, B. (2004). The warehouse prison: Disposal of the new dangerous class. New York, NY: Oxford University Press. 
Jewkes, Y. (2012). Autoethnoraphy and emotion as intellectual resources: Doing prison research differently. Qualitative Inquiry, 18, 63-75. 